\title{
A festa dos canos e a noite das facadas: a pesquisa etnográfica e o estatuto das falas dispersas no campo ${ }^{1}$
}

\section{The pipes party and the stabbing evening: the ethnographic research and the dispersive discourses statute in field research}

\author{
Marcelo de Almeida Ferreri* \\ Professor do Departamento de Psicologia e do Mestrado em Psicologia Social da \\ Universidade Federal de Sergipe - UFS, Aracaju, SE, Brasil

\section{Maria Teresa Nobre **} \\ Professora do Departamento de Psicologia e do Mestrado em Psicologia Social da \\ Universidade Federal de Sergipe - UFS, Aracaju, SE, Brasil
}

\begin{abstract}
RESUMO
O artigo analisa o estatuto dos discursos dispersos num campo, que geram, inesperadamente, algum tipo de redefinição no direcionamento de uma experiência de pesquisa. Trata-se de uma reflexão acerca do lugar do acontecimento e da regularidade no curso da investigação etnográfica, na qual se aponta a importância da sensibilidade do pesquisador ao registrar não somente as falas esperadas, como também aquelas que se pronunciam de modo imprevisto e incidem diretamente na construção do objeto e no desenvolvimento do estudo. Para isso, os autores descrevem a experiência vivida em um estudo sobre a violência no campo da rede de saúde pública, realizado em um bairro periférico em Aracaju/Sergipe. Partindo da apresentação da experiência de campo, passando pelo debate acerca da pesquisa etnográfica e pela exposição do escopo da pesquisa, o texto procura evidenciar como um dado acontecimento discursivo do campo se torna um acontecimento no âmbito da produção de conhecimento em pesquisa.
\end{abstract}

Palavras-chave: Trabalho de campo, Falas dispersas, Etnografia, Violência e saúde.

\section{ABSTRACT}

The article provides an analysis of the dispersive discourses statute in a field which, unexpectedly, produces some type of redefinition in the conducting of a research experience. It is a reflection on the place of the event and on its regularity in the course of the ethnographic investigation, which shows the importance of the researcher's sensibility while registering not only the expected speeches, but also those which are delivered in an unexpected way and affect directly the construction of the object and the study development. In order to do so, the authors describe the experience lived in a study on violence 
in the basic health assistance system made on an outskirt of Aracaju / Sergipe. Beginning with the presentation of the field experience, going through debate on the ethnographic research and through the exposition of the research scope, the text tries to put into evidence how a given discursive event turns into an event in the field of knowledge production in research.

Keywords: Field work, Dispersive speeches, Ethnography, Violence and health.

"[...] temos que ouvir o ronco surdo da batalha". Michel Foucault

\section{Introdução}

Para desfazer a estranheza do título do artigo - que estaria mais para folheto de cordel do que para artigo acadêmico - somente uma sucinta descrição da situação de campo que o inspirou. O cenário é amplo e agitado. Caminhões carregados de pesado material de obras, imensas tubulações amontoadas ao longo da via, grande movimentação de operários realizando a trabalhosa descarga do material, um largo palanque em construção ao lado da área de descarga das manilhas e demais tubos e, no meio disso, a curiosidade das nossas alunas/pesquisadoras que iam em direção à unidade básica de saúde da região: "- o que está havendo aqui hoje?". "São os canos da obra e o palco da festa" - responde um primeiro informante. "Essa noite vai ter facada" - complementa um segundo.

Estamos em um bairro da periferia da cidade, em Aracaju, Sergipe, distante do centro urbano e com características rurais. Segundo depoimentos dos moradores mais antigos, a história do lugar começa com o confisco por dívidas bancárias, de uma chácara de donos de uma empresa de camarão. A partir de então, o terreno abandonado, tornouse área de invasão, ocupada por imigrantes rurais e por outros "sem teto" de várias regiões da cidade. As narrativas sobre o surgimento do bairro evocam a precariedade das condições de habitação, numa área próxima ao manguezal, com poucas casas de alvenaria, muitos barracos de papelão e plástico e a presença constante da criminalidade e insegurança. As primeiras invasões e apossamento dos lotes vão dando lugar, progressivamente, à venda dos barracos e a troca dos terrenos invadidos, por objetos de uso, como bicicleta, eletrodomésticos e similares, adquiridos pelas novas famílias que se fixam no local. Com isso, "foi havendo uma seleção natural dos moradores, os malandros foram deixando a área e foram ficando as famílias". As condições precárias de moradia e infraestrutura, contudo, continuaram existindo, 
não obstante algumas iniciativas governamentais ligadas à pavimentação, construção de conjuntos habitacionais e instalação de alguns equipamentos públicos, como escola, posto policial e unidade básica de saúde.

O diálogo registrado pelas alunas/pesquisadoras, descrito no início do artigo - que relaciona uma ocasião de festa a prováveis confrontos violentos entre os moradores - , consiste em uma cotidiana cena de pesquisa, uma daquelas situações de investigação que poderia ser desprezada nos diários de campo, não fosse a desconcertante contradição que ela sugere. Tal desconcerto diz respeito ao estudo da violência numa comunidade da periferia urbana: a chegada do que representa melhoria na qualidade de vida daquela população evoca, de imediato, a suspeita do recrudescimento da degradação. Melhor dizendo, do imaginário das ações em saúde, onde saneamento básico significaria diminuição da violência, para a efetivação das medidas que melhorem as condições de vida, o fenômeno da violência guarda inesperadas facetas que mostram o equívoco de certas causalidades incautas.

Com o adensamento populacional na região, que não foi acompanhado por melhorias das condições de urbanização, houve o acirramento da imagem do bairro como "muito violento", tanto pela mídia, quanto pela população. Isso porque, mais recentemente o lugar passou a abrigar fugitivos da penitenciária, com regiões de tráfico de drogas próximas ao mangue, ruas estreitas, becos e vielas inacessíveis, que dificultam o trânsito de automóveis e pedestres e que coloca qualquer transeunte, (inclusive os profissionais de saúde em visitas domiciliares), na mira dos "bandidos". Nesse cenário de medo e insegurança, a urbanização e o saneamento básico apareciam nos discursos ouvidos na pesquisa como condições indispensáveis para redução da criminalidade e garantia de segurança às pessoas que moram, trabalham e circulam na região. $O$ mito do "saneamento pacificador" que se repetia nos relatos dos moradores, entretanto, parecia se desvanecer diante da "festa dos canos", apontando a fragilidade da argumentação "o saneamento salva a comunidade da violência", e, por conseguinte, a fragilidade das explicações de causa-efeito para problemas complexos, tais como: a formação de bairros periféricos aos centros urbanos, o desemprego, as precárias condições de moradia, a falta de equipamentos públicos e seu mau funcionamento, a falta de projetos de futuro e opções de lazer dos jovens, entre tantos outros impasses da vida cotidiana e suas possíveis relações com a criminalidade e com a banalização das práticas violentas encontradas nesta e em outras regiões da cidade. 
A pequena, rápida e inesperada "passagem" apreendida nos registros das alunas/pesquisadoras, que abre este artigo, provocou impactos na experiência de pesquisa que ora apresentamos, e nos levaram a repensar alguns aspectos da investigação, conforme mencionaremos mais adiante. Sobretudo, o comentário da "noite das facadas" nos faz pensar sobre a prática da pesquisa etnográfica, o fazer do pesquisador ao construir seu campo de investigação e a sutileza de sua percepção que pode gerar impactos na produção de conhecimento. O objetivo desse artigo é refletir brevemente sobre esses aspectos da etnografia, especialmente sobre a relação que o pesquisador estabelece entre material teórico e empírico da pesquisa e alguns dados que, a princípio, seriam residuais na proposta de estudo. Trata-se especialmente de pensar sobre o lugar das falas esperadas dos participantes na investigação e o de outras "vozes" que surgem no campo.

\section{Atentando para os imponderáveis do campo: de que falam os acontecimentos?}

Muito já se disse sobre o quanto o campo é fundamental na pesquisa etnográfica, principalmente no que tange ao seu significado de ruptura com o conhecimento abstrato e especulativo. As práticas da observação (especialmente a de caráter participante) e do registro exaustivo das experiências pelo pesquisador marcaram as ciências sociais já no início do século passado, trazendo novas possibilidades para a investigação dos fenômenos humanos, pois, com elas, se assume claramente a construção de um tipo de conhecimento que provém da relação do observador com o observado. Na visão de Laplantine, o etnógrafo deve ser capaz de vivenciar em si a "tendência principal da cultura que estuda" já que a etnografia nada mais é que uma experiência de imersão profunda no campo de investigação. Nesse sentido, o pesquisador não se fecha em uma programação estrita de seus procedimentos e na utilização de protocolos rígidos, mas se permite uma certa busca errante no campo, uma experimentação em sentido amplo, condição própria do olhar etnográfico (LAPLANTINE, 2006).

Esse diferencial de investigação foi ressaltado tanto pela antropologia do século passado como por parte da sociologia desse mesmo período. Em meio às investigações sobre a constituição da cultura tribal na antropologia inglesa, Malinowski (1978) definiu como objetivo principal da etnografia estabelecer o contorno firme e claro dos fenômenos culturais para delinear suas leis e padrões, a partir de um levantamento geral dos fenômenos do campo pelo pesquisador que se diferenciasse de um registro sensacionalista. Cabia ao etnógrafo, portanto, analisar não somente o estranho e admirável, mas também (e, sobretudo) o comum 
e rotineiro. Para ele, esse olhar etnográfico dota de "carne e sangue" a pesquisa científica que, sob outras modalidades de investigação, só é capaz de traçar o "esqueleto" dos fenômenos (MALINOWSKY, 1978). Da mesma forma que na pesquisa sobre as culturas tribais, o estudo do homem urbanizado das cidades também poderia ser beneficiado por este tipo de olhar encarnado. Robert Park defendia, já nos primeiros estudos sociológicos da Escola de Chicago, que o mesmo método paciente e interessado dos antropólogos sobre os índios poderia ser utilizado junto ao habitante da urbe com possibilidade de "maior sucesso na investigação dos [seus] costumes, crenças, práticas sociais e concepções gerais de vida" (PARK, 1967, p. 31).

Outro aspecto bastante ressaltado da pesquisa etnográfica é o esforço para mostrar a multidimensionalidade dos fenômenos singulares e concretos que investiga. Tal esforço, que parte da preocupação de levar em conta tudo o que ocorre no campo mesmo que não diga respeito diretamente ao assunto estudado (e que leva o pesquisador a observar, anotar e vivenciar com cuidadosa atenção suas experiências), conduz à formulação de uma totalidade complexa - e muitas vezes inconsciente do objeto, que no mais das vezes constitui o produto diferenciado dessa abordagem de pesquisa menos diretiva e programática de investigação. Essa preocupação com a totalidade dos fenômenos culturais já se apresentava nos estudos de Malinowski. Entretanto, esse esforço não impede opções teóricas pelo pesquisador. A idéia de sistema social, por exemplo, embasou vários estudos etnográficos da sociologia funcionalista americana. Lapassade notou uma convergência metodológica entre as perspectivas do interacionismo simbólico, da etnometodologia e da análise institucional em torno do interesse pela capacidade instituicionalizante da ordem social, destacando a valorização da abordagem qualitativa, do uso dos diários de campo e da implicação do pesquisador com seu trabalho (LAPASSADE, 2005).

Para a reflexão em curso nessas linhas, o ponto fundamental da preocupação com a totalidade do registro dos fenômenos é o do lugar do acontecimento frente às regularidades do campo, do inesperado e seus efeitos na pesquisa, aspecto da etnografia que nos remete diretamente à fala da "festa dos canos" do início do texto. A missão de apreender o rotineiro e comum do objeto, obriga, por outro lado, o pesquisador a atentar para a relação com os eventos que ocorrem inesperadamente no campo, inclusive os inesperados não só para a pesquisa, como para o próprio campo. Laplantine afirma que esse encontro com o acontecimento imprevisto é freqüente nesta abordagem. Contudo, para evitar relatos sensacionalistas da investigação, o acontecimento deve ocupar lugar ao lado daquilo que é regular e 
cotidiano no campo, de modo que não desvie o olhar sobre o costume, o típico e familiar, compondo um registro de totalidade do campo (LAPLANTINE, 2006). Ao mencionar uma perspectiva de apreensão da totalidade do campo, o autor não tem a pretensão de esgotar a sua complexidade, mas remete às múltiplas e exaustivas possibilidades de acercamento do objeto de estudo, tantas quantas sejam as configurações que um campo oferece. A esse processo Magnani (2003) chama de busca por uma "saturação nos resultados" efeito que se obtém quando, a partir de diferentes procedimentos, os dados começam a reiterar-se.

Malinowski (1978) sustenta que o alcance dos objetivos da pesquisa etnográfica ocorre através de três caminhos metodológicos: pelo registro do arcabouço da constituição do objeto (da tribo, no caso); pelo registro dos imponderáveis da vida real ou do comportamento típico; e pelo registro da mentalidade nativa. Sobre o primeiro caminho, o autor indica que ele se constrói a partir de um quadro geral claro e preciso que poderia ser delineado a partir de documentação concreta e estatística da vida dos sujeitos (a que chamou de "esqueleto" do campo). Já em relação ao segundo, aponta que ele diz respeito ao registro da intimidade da vida dos sujeitos, o que só é possível obter pela observação minuciosa e detalhada da vida nativa. Imponderável aqui significa não o acontecimento, o inesperado, mas a minúcia do cotidiano desprezada por outros modos de investigação científica (o que seria "a carne e o sangue"). O último caminho consiste na apreensão dos discursos, narrativas típicas e modos de dizer, palavras características e elementos que comporiam a mentalidade coletiva e que, através da linguagem, atribuem sentido aos acontecimentos (o espírito do campo).

Essa busca faz com que a apreensão do campo ocorra, conforme Laplantine, através de uma percepção intensa, uma integralidade dos sentidos do pesquisador. Para o autor, a descrição etnográfica não se limita à percepção visual dos fenômenos. A "visibilidade" do pesquisador é além de ótica, olfativa, tátil, gustativa e auditiva (LAPLANTINE, 2004). Diante disso, podemos apontar como a fala da "festa dos canos" (experiência auditiva por excelência) surte como acontecimento na visão sobre o campo de pesquisa, sobre a violência nas práticas da atenção básica em saúde. Tal efeito de acontecimento tem, como já dissemos, dois planos de repercussão: o primeiro sobre o próprio campo, pela chegada do material da obra e a festividade anunciada pela construção do palanque; a segunda relacionada à estruturação da pesquisa e a ordem de valor das declarações dos sujeitos do campo. Sobre a repercussão no campo, podemos entender seu efeito ao considerar o 
que já foi apresentado sobre o local onde ocorreu a pesquisa; a dura realidade das comunidades mais desfavorecidas nas cidades acaba impondo como acontecimento qualquer medida de saneamento básico pela ação do poder público, tendo em vista as recorrentes condições precárias da vida de seus habitantes. Contudo, para compreender esse efeito na estrutura da pesquisa, é necessário apresentar os elementos constitutivos do estudo em questão para, então, perceber o inesperado da "noite das facadas" na investigação.

\section{As tribulações do trabalho de campo: dos nossos objetos e seus modos de acercamento}

Os longos anos de inserção junto à Segurança Pública do Estado de Sergipe em trabalhos de pesquisa-intervenção como docentes e, por muito tempo, membros da Comissão de Direitos Humanos da UFS, sempre nos afastaram de explicações causais lineares entre pobreza e criminalidade e de outras discussões ligadas à chamada "violência estrutural". No momento em que iniciávamos uma nova pesquisa sobre a violência na rede de saúde pública, os murmúrios e burburinhos vindos do campo ao mesmo tempo em que nos confirmavam esse percurso de análise, nos indicavam que pensar possíveis problematizações sobre "causas" e "tipos" de violência era o grande desafio, ou melhor, dizendo, a impossibilidade que aquele acontecimento nos apontava. Mais do que isso, e como lastro da discussão, estava a própria definição do que vem, ou viria a ser, o conceito de violência "aplicado" ao campo da pesquisa.

Longe de ser consensual, a definição de violência tem causado muita discussão e polêmica no âmbito das ciências humanas e sociais, cujos dissensos circulam, sobretudo, em torno da idéia de violência como prática intencional, uma vez que ações violentas podem ser praticadas como resultado de relações agressivas que se naturalizam e são reproduzidas de modo autômato, sem a deliberação de provocar dor ou sofrimento. Por outro lado, o exercício deliberado da violência pode utilizar-se de alta tecnologia, como em alguns tipos de tortura, aplicada para provocar danos profundos e irreparáveis ou mesmo a morte, sem sofrimento físico. Também discutível é o conceito de violência associado à noção de legitimidade: ela seria classificada como legitima quando usada pelo Estado e como ilegítima quando usada no âmbito da vida privada ou pública, por agentes desautorizados. Outra fonte de divergência é o uso do conceito associado à justificação ou ao critério de mal-menor, como meio para alcançar fins socialmente desejáveis. Todos esses aspectos apontados por OUTHWAITE; BOTTOMORE; GELLNER; NISBET; TOURAINE (1996) apontam a necessidade de uma análise 
criteriosa dos acontecimentos que circundam/produzem a violência, o que nos leva a procurar nortear a discussão pelos seus aspectos éticos, afastando as pretensões à neutralidade e ao relativismo. Leva-nos também a pensar a violência como relação que, assim como o poder, não é um atributo pessoal, que alguém detém e invariavelmente exerce sobre outro. A violência surge quando o discurso está falido, quando ele não produz mais, na relação entre as pessoas, a capacidade de convencimento, adesão ou pactuação, dando lugar ao uso da força como meio de resolução dos conflitos.

A idéia central que pretendemos apontar dá-se em torno do questionamento da idéia de que a violência é capaz de conferir poder ao indivíduo, aos grupos ou ao Estado. Procuramos, assim, ao adotar o conceito de violência como oposto de poder (ARENDT, 1994), pensá-la como relações agressivas que se naturalizaram e tornaram-se banalizadas, nas quais o componente da crueldade toma centralidade. A maior privação dos grupos excluídos é a de falta de acesso aos dispositivos de poder que conferem reconhecimento social, dizem Elias e Scotson (2000). Deste modo, as relações agressivas que se expressam como eventos bárbaros e cruéis, parecem estar relacionados, não a causas econômicas, sociais, culturais, psicológicas ou patológicas, mas à presença de um código social que confere um sentido às práticas violentas. Sendo assim, também não representam "escolhas" por um estilo de vida violento, pelo contrário, dizem respeito à circunstâncias que são prescritas e limitadas a tensões e conflitos que se desenvolvem numa dada sociedade. A direção que tomam vai depender fundamentalmente das relações de poder e dominação e das possibilidades de resistência a elas (FOUCAULT, 2003; DE CERTEAU, 1999). Nesse sentido pensamos as violências (no plural) como relações e práticas que independentemente das intenções do seu autor produzem efeitos de aniquilamento, destruição ou danos profundos a uma pessoa, sejam eles físicos, psíquicos, morais ou materiais (CHAUí, 1985).

A partir do fim da ditadura militar, com o processo de redemocratização do País, o problema da violência passou a receber uma atenção diferenciada no campo da saúde. A partir de efeitos das lutas sociais, de uma nova configuração político-institucional do poder público, dos reflexos sociais e econômicos de transformações na ordem das relações de produção, a assistência à saúde a pessoas em situação de violência vislumbrou novos horizontes para o âmbito de suas práticas. Esse quadro, de uma forma geral, pode ser visto sob dois importantes aspectos correlacionados: ampliação do enfoque para além do tratamento de lesões, acidentes e traumas e a inclusão desse tipo de assistência na agenda dos direitos sociais almejados no campo da 
saúde, seja para casos de violência ocorridos no espaço da vida privada, seja para efeitos da ação do Estado contra cidadãos. Essa mudança de rumo tem se dado, entretanto, de forma lenta e intermitente, caracterizando-se como um processo ainda inconcluso e sob pressão de vários atores, sobretudo dos movimentos sociais (MINAYO, 2007).

Com efeito, progressivamente, a violência urbana, doméstica e sexual passaram a ser consideradas problemas de saúde pública, acrescentando-se a isso os elevados índices de mortalidade e morbidade que tem estes fenômenos como causa (MINAYO; SOUZA, 1998, 2003; SCHARAIBER; D'OLIVEIRA, 1999). Outros fatores que contribuíram para a aproximação entre violência e saúde, decorrem dos elevados custos que o Estado brasileiro tem destinado ao atendimento dos casos de violências na rede de saúde pública (MIR, 2005), como também pelo aumento dos índices de mortalidade e morbidade por causas externas, pelo sofrimento e stress que o trabalho de assistência tem gerado nos profissionais que atendem a pessoas nessas situações (MINAYO, 2007) ou ainda em virtude da pressão do Ministério Público, da Polícia e da J ustiça, para que a rede de saúde notifique compulsoriamente esse tipo de atendimento e capacite seus quadros para que prestem assistência qualificada a esses casos.

A reflexão sobre a atualidade da inserção da violência no campo da saúde foi perpassada integralmente pela discussão a respeito das políticas públicas, aqui entendidas como ações desenvolvidas pela máquina do Estado (programas, projetos, regulamentações, leis e normas, princípios e diretrizes) para administrar diferentes interesses sociais. São, portanto, ações que se pretendem afirmativas, no sentido de oferecer respostas às necessidades e demandas de alguns setores da sociedade, resultado das lutas sociais e que paradoxalmente garantem a manutenção do próprio capitalismo, sem as quais ele implodiria (FALEIROS, 1982). Implantadas sempre sob pressão dos movimentos sociais ou de outros segmentos, a sua implementação guarda invariavelmente uma distância entre o projeto original e o que é de fato instituído, constituindo-se, assim, em um campo de embates, disputas e negociações, no qual os grupos interessados, muitas vezes vulneráveis, pessoas em situação de risco, e agentes institucionais - usuários, gestores e trabalhadores - comparecem, em posições desiguais, em função dos diferentes lugares que ocupam, das suas implicações e objetivos e das relações de poder que se produzem no cenário desses confrontos.

O modelo de atenção básica adotado pela rede municipal de saúde em Aracaju inclui equipes de referência integradas pelo Programa de Saúde da Família (PSF) e outras equipes de referência territorial, de natureza 
multiprofissional, que atuam no espaço das unidades básicas de saúde (UBS) e na comunidade a ela adscrita. Os profissionais integrantes dessas equipes devem realizar tarefas de acolhimento aos usuários (tecnologia voltada à escuta inicial de todos os pacientes, solução dos problemas mais simples e agendamento dos atendimentos de acordo com a classificação de riscos), consultas individuais e atenção domiciliar. Esse novo arranjo organizacional pretende garantir o acesso e a integralização dos procedimentos de cuidado aos usuários, evitando a prática dos encaminhamentos para outras unidades ou centros de saúde, nos quais, geralmente, se fragmenta o atendimento e se perde o vínculo profissional-usuário (BRASIL, 2004). Essas equipes são matriciadas pela Rede de Saúde Mental, cujos principais equipamentos de assistência são os Centros de Atenção Psicossocial (CAPS), serviços voltados aos portadores de transtornos mentais. Além de atenderem esses usuários as equipes da rede de saúde mental devem oferecer um suporte institucional aos profissionais da atenção básica e, sobretudo, às equipes dos PSFs que lidam com esses problemas, incluindo casos de violência.

Pesquisa realizada por Tard (2006) conclui que o atendimento em um território delimitado, como ocorre com as equipes do PSF, favorece a construção de vínculos com os usuários, como conseqüência de contatos mais freqüentes e de uma relação mais continuada no tempo. Além disso, o desenvolvimento de um trabalho domiciliar permite 0 conhecimento, compreensão e enfrentamento dos problemas vivenciados pelas famílias, a partir do estabelecimento de laços de confiança entre usuários-profissionais, que deveriam favorecer a construção de projetos terapêuticos singulares no campo da saúde mental e de enfermidades que possuem fortes determinantes afetivos e sócio-culturais.

Considerando esse modelo de atenção à saúde, a hipótese de trabalho da pesquisa que realizamos é de que os profissionais das equipes dos PSFs e particularmente os agentes comunitários de saúde são os que mais conhecem a problemática da violência doméstica e de outras formas de violência que atingem os usuários que estão sob seus cuidados. Ao penetrarem na intimidade das famílias esses profissionais adentram um universo de queixas e demandas que, mesmo se configurando como problemas de saúde pública, não são endereçadas aos serviços de saúde, a menos que tragam conseqüências graves ou muito graves do ponto de vista físico ou psíquico. Assim, a pesquisa pretendeu, por um lado, mapear o trabalho desenvolvido nas UBS, visando identificar as demandas implícitas e explícitas relacionadas à violência dirigidas pela população à rede de saúde pública no âmbito da 
atenção básica e, por outro, as práticas institucionais desenvolvidas nas UBS voltadas ao atendimento dos casos de violência, sobretudo pelas equipes de PSFs e em particular, pelos agentes comunitários de saúde (ACS). Tomando as premissas teóricas que adotamos em torno das noções de violência, poder, resistência e desvitimização, a perspectiva de análise deste trabalho foi a de interpelar os casos de violência que chegam à rede de saúde pública como modo de enfretamento que retira as pessoas da invisibilidade, e, portanto, da condição de passividade e que tem, nas práticas dos agentes comunitários de saúde, uma escuta privilegiada.

Portanto, por essa ótica fica clara a ordem de valor das falas dos sujeitos no campo: os profissionais de saúde do PSF e, primordialmente, os agentes comunitários, sua visão e proximidade com a violência. $O$ privilégio da fala desses sujeitos foi assegurado com entrevistas semiestruturadas que buscaram apreender o discurso desse conjunto de profissionais sobre o objeto de pesquisa.

A inserção em um campo de pesquisa, porém, é um trabalho lento, desafiador e cheio de "tribulações" (MALINOWSKI, 1978), que começam quando o pesquisador, ainda que trabalhe em equipe, se vê sozinho e desamparado em meio àquilo que desconhece, por mais que faça parte de uma experiência ou situação: trata-se sempre de se sentir estranho e estrangeiro, precisando dizer a que veio e negociando trocas, diante da questão sempre infalível que os "nativos" nos colocam: "Sim, mas o que vocês vão fazer com esses resultados? Em que eles ajudam ao nosso trabalho? O que isso vai trazer de melhoria à comunidade?". Compromisso firmado de devolução dos dados pesquisados, para "pensarmos juntos no que eles sugerem ou querem dizer", obtivemos a autorização dos atores locais e "sujeitos" da pesquisa a iniciá-la. A essas tribulações iniciais, se junta a burocracia institucional que atravessa nossas intenções e tentativas de conhecer de perto o funcionamento da máquina estatal, quando pesquisamos organizações de prestação de serviços públicos: percursos infindáveis com muitas idas e vindas, entre conversas de gabinetes e ofícios que se impõem como necessários e circulam sobre as mesas dos gestores, mesmo quando a negociação de entrada no campo já foi pactuada com os atores locais, no nosso caso, trabalhadores da UBS que pretendíamos conhecer.

Nada disso, entretanto, parece ser garantia de sucesso no trabalho. A autorização formal e informal para entrar no campo está muito longe de representar confiança e reconhecimento dos atores locais ao que nós possamos dizer ou fazer, e também, ao que nos será permitido ver e ouvir. No caso desta pesquisa que pretendia investigar como a rede de saúde pública lida com as relações de violência no território onde presta 
serviços - tema árido e visto como tabu, do qual ninguém se sente à vontade para falar - outros percalços nos esperavam, sobretudo o questionamento do porquê havíamos escolhido aquele bairro e aquela UBS, querela em torno da qual os trabalhadores se dividiam. Entre os que moravam na própria comunidade ou haviam se comprometido afetiva e politicamente com ela, haviam duas posições: uns contestavam; afinal, "índices de criminalidade são altos em outros bairros da cidade, inclusive nas áreas nobres", e essa fama de bairro violento "é coisa da mídia, que tem a ver com o tempo da invasão; agora não é mais assim, é um bairro como outro qualquer". Outros, sobretudo os agentes comunitários de saúde, reconheciam os altos índices de violência e por isso mesmo queriam saber se nós pretendíamos identificar pessoas e locais onde esses eventos ocorriam. Colocando-nos na posição extremamente incômoda de "olheiros", diziam que não iam revelar nada, afinal "tinham a confiança da comunidade, coisa que demoraram a conquistar". Alegavam que as pessoas querem ajuda, desejam resolver as situações e reduzir ou eliminar o índice das agressões cotidianas, da insegurança, da violência, mas não pretendem criminalizar seus autores ou passar à tutela do Estado.

Identificamos os dois enunciados como analisadores importantes: o primeiro parecia indicar "uma defesa" da comunidade, uma negação do estigma que carrega, o que nos sugeria uma prática de resistência frente à imagem produzida pela mídia, a reivindicação de que ali morava "gente de bem" e a denúncia de que o problema da criminalidade não pode ser associado à pobreza das áreas periféricas dos centros urbanos. O segundo demandava um olhar e uma escuta mais apurados, afinal, com essa posição, os agentes comunitários de saúde tomavam claramente um partido contrário à política de enfrentamento da violência recomendada pelos gestores da saúde pública, para a qual a notificação da violência é estratégia fundamental, cuja omissão implica, inclusive, em penalidades ao profissional.

Pesquisadores expostos diante de uma audiência que nos indagava, questionava e desafiava, nos restou anunciar claramente as nossas posições políticas: nossa descrença absoluta de que a denúncia e a conseqüente criminalização e punição aos agressores seja o caminho a ser seguido para a redução da violência, a nossa desconfiança nas ações ditas protetivas, inclusivas ou assistências das organizações policiais e jurídicas que compõem a máquina do Estado e a garantia do nosso sigilo frente aos dados colhidos na pesquisa, que seriam apresentados aos sujeitos que dela participaram, para que deles se apropriassem e deles fizessem uso. 
Compromisso firmado publicamente foi possível iniciar as conversas e entrevistas com os trabalhadores da UBS, com os usuários da rede de saúde e acompanhar os agentes comunitários em visitas domiciliares em sua rotina de trabalho na comunidade, recursos que garantiram a nossa imersão etnográfica no campo. O contato esperado entre pesquisadores, profissionais, usuários de saúde e agentes comunitários durante as visitas, com seu respectivo registro, tornou esse procedimento ocasião para privilegiar a fala desses sujeitos na pesquisa. É frente a esta ordem de valor das falas que as vozes dispersas autoras da "festa dos canos" se tornaram acontecimento na pesquisa.

\section{Considerações Finais: o murmúrio tornado palavra, efeito político na pesquisa?}

A fala como elemento suficiente para sustentação dos achados em pesquisa é questão de difícil consenso no âmbito da metodologia científica. É bem vasta a discussão que trata do estatuto do depoimento na produção de conhecimento, especialmente no que tange às ciências humanas e sociais. O debate sobre o uso apropriado de procedimentos metodológicos (como entrevista, observação, combinação entre esses ou desses com outros) acirra ainda mais a reflexão sobre o valor científico dos discursos, relatos ou outro termo que designe a verbalização dos sujeitos. A partir da preocupação com o problema da inferência e da prova a partir de observação em pesquisa de campo, Becker (1999) traz algumas contribuições à questão da fala em pesquisa, na medida em que estabeleceu alguns estágios de pesquisa através dos quais tornou viável a análise do problema da inferência e da prova. Tais estágios são: a seleção e definição de problemas, conceitos e índices; o controle sobre a freqüência e a distribuição dos fenômenos; e a incorporação de descobertas individuais em um modelo da organização em estudo. Escapa aos limites desse texto explicar cada um dos estágios, porém é no tratamento do primeiro estágio que o autor toca no problema da credibilidade de informantes e de suas declarações no campo de pesquisa.

Becker mostra que as declarações do informante não devem ser tomadas por seu valor literal e, a partir disso, como evidências suficientes na pesquisa de campo. Para tornar as declarações evidências, o pesquisador precisa estabelecer critérios para o exame das falas. Ele chama atenção para o fato de que mesmo uma declaração "defeituosa" sobre um acontecimento pode fornecer evidências úteis para algum tipo de argumentação na pesquisa. Assim, as "declarações e descrições obtidas no campo podem ser tratadas como indicações da perspectiva do indivíduo sobre o ponto em questão" (BECKER, 1999, p. 
53). Vistas como indicações, o autor passa a tratar das declarações a partir de suas qualidades, diferenciando as espontâneas das dirigidas. As declarações espontâneas teriam um valor de evidência maior que as declarações dirigidas, pois essas últimas estariam mais sujeitas às condições impostas pelo pesquisador no fazer de sua investigação, enquanto que as primeiras possuem um caráter mais imprevisto no campo. Nesse sentido, o estatuto de acontecimento de uma declaração fortalece seu valor como prova e favorece as possibilidades de inferência decorrente do material espontâneo do campo. Contudo, essa valorização está atrelada a uma qualificação dos informantes (fundamental sem dúvida) e a qualidade declaratória do depoimento (cuja espontaneidade adquire privilégio).

A fala da "festa e dos canos" e "da noite das facadas", embora plenamente acontecimento, não respondem ainda aos quesitos apontados por Becker: devem, portanto, ser descartadas do conjunto de dados do campo? Como desprezar, então, a descontinuidade de causa/efeito, de problema/solução trazida em seu bojo, descontinuidade essa que marca o enfrentamento do tema da violência em uma perspectiva não reducionista, não simplista? A condição rebuscada e contraditória da violência, afirmada na declaração da "noite das facadas", assinala mais do que boa parte dos depoimentos "qualificados" dos sujeitos da pesquisa, a dificuldade que nossas experiências de pesquisa anteriores encontraram em campos distintos da atenção básica em saúde. Que lugar, então, oferecer para esses sujeitos não previstos na pesquisa?

Embora não esteja no rol dos autores que tratam diretamente da etnografia, Foucault (1999) oferece uma importante contribuição para a questão em Ordem do Discurso, ao afirmar a importância de dar a palavra ao murmúrio dos discursos que ficam de fora dos lugares estabelecidos pela ordem das coisas. Contra a ordem que autoriza determinados discursos e desautoriza outros na distribuição dos lugares e dos poderes, seria hora de dar voz às falas que não encontram lugar entre os discursos que são enunciados em uma dada relação de forças. Talvez não seja propriamente o caso de definir como luta política a ordem de valores que se põe entre sujeitos previstos e imprevistos na pesquisa de campo, mas encontramos em Foucault um franco convite para redimensionar o lugar dos discursos dispersos do campo que ficam de fora dos relatórios finais das etnografias. Especialmente quando o pesquisador se permite apreciar o impacto de certas declarações no desenho da pesquisa. Passemos, então, ao efeito direto que a "noite das facadas" operou em nosso estudo sobre a violência nas práticas da atenção básica em saúde. 
De um modo geral, o tratamento do tema da violência em diversas áreas das políticas públicas passa pelo levantamento de categorias como "causas", "justificativas", "tipos" e "soluções", categorias essas que sustentam a expectativa de que haja uma ação programática das políticas que seja suficiente para produzir resolutividade ao problema. $\mathrm{O}$ campo da saúde não parece agir de forma diferenciada, alimentando a ordem discursiva que torna a violência um objeto suscetível a linearidades do tipo causa/efeito, diagnóstico/solução. Apesar do pouco tempo da incorporação da temática da violência pela área da saúde, já estão bem difundidas nesse campo as idéias de prevenção como saída para os danos da violência, assim como o uso de tipologias de violência como caminho de enfrentamento da questão. Da mesma forma que a "noite das facadas" golpeia, a nosso ver, a expectativa de um saneamento pacificador, derruba também uma concepção linear de objeto para a violência que não leve em consideração suas contradições e sua multidimensionalidade.

Diante da cortante declaração da "noite das facadas" em seguida à "festa dos canos" decidimos recusar a cilada da linearidade das categorias de investigação convencionais dos estudos de violência e adotamos a idéia de "produção de violência" como índice analítico dos dados do campo. Produção, não para localizar algum princípio gerador, um ponto central de onde emane seus efeitos, mas para descrever o campo discursivo dos atores da saúde (profissionais e usuários) nas práticas de atendimento a pessoas em situação de violência. Desta forma, o efeito de assimilar a noite das facadas leva também à recusa de "teses" sobre a violência que alimentam a mentalidade excludente que advém dos determinantes sociais relacionados ao problema, como a idéia de pobreza como geradora de violência, de que a urbanização é a solução para favelas e comunidades precarizadas, de que a violência decorre da falta de medidas punitivas (para as quais o incentivo à notificação seria o primeiro passo para uma resolução). Eis, então, que a fala dispersa dos declarantes inesperados que se pronunciaram no canteiro de obras contribuem festivamente para o aprimoramento do olhar etnográfico do pesquisador, que ao lhe dar atenção em seus registros e no desenvolvimento da investigação, escapa das facadas contínuas da debilização do debate sobre a violência.

\section{Referências Bibliográficas}

ARENDT, H. Sobre a violência. Rio de J aneiro: Relume-Dumará, 1994. BECKER, H. S. Métodos de pesquisa em ciências sociais. 4. ed. São Paulo: HUCITEC, 1999. 
BRASIL. Ministério da Saúde. Núcleo Técnico da Política Nacional de Humanização. "Humaniza SUS: a humanização como eixo norteador das práticas de atenção e gestão em todas as instâncias do SUS". Série B. Textos básicos de saúde, Brasília, 2004.

CHAUÍ, M. Participando do debate sobre mulher e violência. In: CHAUÍ, M.; CARDOSO, R.; PAOLI, M. C. (Orgs.). Perspectivas antropológicas da mulher, v. 4. Rio de Janeiro: Zahar, 1985, p.23-62.

DE CERTEAU, M. A invenção do cotidiano. Petrópolis: Vozes, 1999.

ELIAS, N.; SCOTSON, J. Os estabelecidos e os outsiders. Rio de J aneiro: Jorge Zahar Editor, 2000.

FALEIROS, V. Políticas sociais do Estado capitalista. São Paulo: Cortez Editora, 1982.

FOUCAULT, M. A ordem do discurso. São Paulo: Loyola, 1999.

Estratégia, poder-saber. Coleção Ditos e Escritos, v.4. Rio de Janeiro: Forense Universitária, 2003.

LAPASSSADE, G. As microssociologias. Brasília: Liber Livro, 2005.

LAPLANTINE, F. A descrição etnográfica. São Paulo: Terceira Margem, 2004.

Aprender antropologia. 18. ed. São Paulo: Brasiliense, 2006.

MALINOWSKI, B. Argonautas do Pacífico Ocidental (Coleção Os pensadores). v. 43. São Paulo: Abril, 1978.

MAGNANI, J. C. C. Festa no pedaço. Cultura popular e lazer na cidade. 3. ed. São Paulo: HUCITEC/UNESP, 2003.

MINAYO, M. C. de S.; SOUZA, E. R. Violência e saúde como um campo interdisciplinar e de ação coletiva. História, Ciências, Saúde, Manguinhos, v. IV, n.3, p. 513-531, nov. 1997/fev. 1998.

MIR, L. Guerra civil. Estado e trauma. São Paulo: Geração Editorial, 2004.

OUTHWAITE, W.; BOTTOMORE, T.; GELLNER, E.; NISBET, R.; TOURAINE, A. (Eds.). Dicionário do pensamento social no século XX. São Paulo: J orge Zahar Editor, 1996.

PARK, R. E. A cidade: sugestões para a investigação do comportamento humano no meio urbano. In: VELHO, O. (Org.). O fenômeno urbano. Rio de Janeiro: Zahar Editores, 1967, p. 29-72

SCHRAIBER, L. B.; D'OLIVEIRA, A. F. L. P. Violências contra as mulheres: interfaces com a saúde. Comunicação, Saúde, Educação, v.3, n.5, 1999, p.11-26.

TRAD, L. A. B. Humanização do encontro com o usuário no contexto da atenção básica. In: DESLANDES, Suely F. (Org.). Humanização dos cuidados em saúde: conceitos, dilemas e práticas. Rio de Janeiro: Ed. Fiocruz, 2006, p.185-203. 


\section{Endereço para correspondência}

Marcelo de Almeida Ferreri

Departamento de Psicologia da Universidade Federal de Sergipe Cidade Universitária, Rua Prof. José Aloísio de Campos s/n, Jardim Rosa Elze, CEP 49100-000, São Cristóvão, SE, Brasil

Endereço eletrônico: marceloferreri@uol.com.br

Maria Teresa Nobre

Departamento de Psicologia da Universidade Federal de Sergipe Cidade Universitária, Rua Prof. José Aloísio de Campos s/n, Jardim Rosa Elze, CEP 49100-000, São Cristóvão, SE, Brasil

Endereço eletrônico: teresa-nobre@uol.com.br

Recebido em: 04/08/2009

Aceito para publicação em: 18/11/2009

Acompanhamento do processo editorial: Deise Mancebo, Marisa Lopes da Rocha e Roberta Carvalho Romagnoli

\section{Notas}

* Doutor em Psicologia Social

** Doutora em Sociologia

${ }^{1} \mathrm{~A}$ pesquisa que serve de base às reflexões deste artigo, intitulada "Violência e saúde: práticas de atendimento a pessoas em situação de violência na rede de atenção básica do município de Aracaju" contou com bolsas do PIBIC/CNPq e com financiamentos da FAPITEC (Fundação de Apoio à Pesquisa e à Inovação Tecnológica do Estado de Sergipe) e do PAIRD (Programa de Apoio Institucional a Recém-Doutores da UFS). Participaram do trabalho de campo as alunas Elisleide Santos Rocha e Fernanda Mayra Mendonça de Oliveira, do Curso de Psicologia da Universidade Federal de Sergipe UFS, às quais registramos nossos agradecimentos 